\title{
EL LIENZO DE UN ESQUIZOFRÉNICO: EL ARTE COMO RELATO \\ SUBJETIVO
}

\author{
The canvas of a schizophrenic: Art as a subjective story
}

Ana Paula Castillo Munguía, Universidad Autónoma de Querétaro, México Correo electrónico: casmun33@hotmail.com

Luciane Loss Jardim, Círculo Psicoanalítico Mexicano, México Correo electrónico: lulossjardim@gmail.com

Recepción: 18/07/2019

Aceptación: 4/2/2020

Resumen. Desde el psicoanálisis, en la psicosis lo que no encontró cabida en la red simbólica retorna en lo real $\mathrm{y}$ tiene efectos de desborde $\mathrm{y}$ fragmentación sobre lo imaginario, que pueden llevar al sujeto a la desintegración gradual de su yo. Nuestro trabajo esboza una lectura psicoanalítica de la obra pictórica del artista esquizofrénico Louis Wain en la cual dicha desintegración puede verse reflejada en la tela del artista, que solía dibujar gatos antropomorfizados, con los cuales se identificaba, una referencia de la imagen de sí mismo. El arte se configura como un saber hacer con el vacío, con los desgarros de lo real. La obra de arte encierra un mensaje sobre el sujeto que escapa a la palabra, pero se captura en la tela como algo que puede ser legible, como un enigma sobre el sujeto que pueda ofrecer una posible interpretación desde el psicoanálisis.

Palabras clave: arte, psicosis, esquizofrenia, psicoanálisis, yo.

\begin{abstract}
From a psychoanalytic perspective, in psychosis that which not found a place in the symbolic network returns in the real and has effects of overflow and fragmentation on the imaginary, which can lead the subject to the gradual disintegration of his ego. Our work outlines a psychoanalytic reading of the pictorial work of the schizophrenic artist Louis Wain in which this disintegration can be seen reflected in the artist's works, which show anthropomorphized cats, with which he identified himself, a reference to his self-image. Art is configured as a know-how with emptiness, with the tears of the real. The work of art contains a message about the subject that escapes the word but is captured on the canvas as something that can be readable, as an enigma on the subject that can offer a possible interpretation from psychoanalysis.
\end{abstract}

Keywords: art, psychosis, schizophrenia, psychoanalysis, ego. 


\section{enn-claves}

\section{Introducción}

El arte puede ser tomado como un decir del sujeto que se coloca en relación con el psicoanálisis, que desde Freud centra su interés en recuperar la pregunta por el lugar que le compete al sujeto, por encontrarle detrás de cualquier etiqueta nosográfica, y que desde él ha buscado proyectar sus aportaciones a diversos ámbitos del quehacer del hombre. Es de nuestro interés la proyección que esto ha tenido en el ámbito de la creación artística.

El análisis de una obra de arte cobra importancia al ser un medio que permite rescatar un decir, en un momento que consideramos impera un reduccionismo biológico que niega o banaliza el papel activo y, en este caso, diríamos creador del sujeto respecto a su padecimiento. En consecuencia, el interés y aportación de nuestro trabajo es mostrar la riqueza de lo que puede aprehenderse y problematizarse con lo que un enfermo mental produce por la vía artística-pictórica. Creaciones que, si bien no son elaboradas con fines terapéuticos, pueden ayudar a comprender la sintomatología de la enfermedad y posibilitar un acercamiento al mundo psíquico del sujeto. Poner de manifiesto lo que más allá de la palabra el enfermo comunica y experimenta en el transcurso de su enfermedad.

En ese sentido, este trabajo contempla una revisión teórica de los procesos psíquicos que llevan a un sujeto a la condición esquizofrénica y el papel que juega lo que se forcluyó en la conformación corporal. Nos centramos en la propuesta lacaniana para entender la esquizofrenia en relación con el significante, el inconsciente estructurado como lenguaje y el Otro. Revisaremos el papel de la metáfora paterna y la inscripción de un significante primordial: El Nombre del Padre y su relación con el advenimiento del yo corporal.

Repasaremos el concepto de forclusión para dar cuenta de cómo es que en la esquizofrenia esa inscripción inaugural no se efectúa y los efectos que produce en el sujeto, alterando la relación con el Otro - dejando vacío-huecos en la cadena, que tienen efectos sobre el cuerpo - para desde ahí buscar los nexos con la obra pictórica y plantear que la fragmentación corporal del esquizofrénico puede verse reflejada en el espejo/lienzo. Es decir, que el argumento de este artículo es que hallamos un bosquejo de la imagen corporal del esquizofrénico en la tela, donde el dibujo/desdibujo de las formas y figuras muestran la desintegración yoica presente en la enfermedad.

Con ello esbozamos el planteamiento del arte en tanto relato subjetivo como un modo de expresión a nivel de lo no verbal, de la imagen. Haremos una breve revisión de la 


\section{enn-claves}

biografía y vida profesional del artista, para de ahí utilizar sus obras como algo legible, como algo susceptible de una posible lectura desde el psicoanálisis. Utilizaremos como referente el cambio en los trazos, colores y formas que van de lo naturalista a lo psicodélico para revisar la relación de su obra con el avance de la enfermedad y los efectos de desintegración sobre la imagen del cuerpo.

Finalmente, proponemos nuestras conclusiones acerca de lo que el lienzo-tela de este artista esquizofrénico tiene en relación con la desintegración yoica presente en la esquizofrenia.

\section{Del espejo a la metáfora paterna}

Según Lacan ${ }^{1}$ el sujeto del psicoanálisis es un sujeto de lenguaje. El lenguaje representa y condiciona al sujeto en la praxis psicoanalítica y está dimensionada por tres registros: real, simbólico e imaginario. lo simbólico es el seno donde toda comprensión se inserta, ejerciendo una influencia directa en las relaciones interhumanas.

Por tanto, el sentido se encuentra en lo que el sujeto dice y lo que ese decir captura. En la palabra está la particularidad. Un sentido que apela al sujeto en relación con sus deseos, su medio, los otros y con la vida misma. Aquello que se teje a través de las palabras, donde el lenguaje es la base.

De este modo, con Lacan, ${ }^{2}$ decimos que el inconsciente está estructurado como un lenguaje, "el sujeto surge donde surge la palabra, con la invención simbólica, bañado por significantes que le otorgan un lugar". ${ }^{3}$ Por lo tanto, el sujeto ordena su experiencia en la medida en que "las relaciones en las que está capturado han alcanzado ellas mismas el grado de simbolismo" "4 pueda entonces interrogarse sobre sí. Es decir, que el sujeto existirá y dará cuenta de los efectos de subjetivación en la medida que se localice dentro de un orden discursivo donde el Grande Otro — tesoro de los significantes - ocupará una

\footnotetext{
1 Jacques Lacan, "Introducción a la cuestión de la psicosis", en El Seminario. Libro 3. Las psicosis. El seminario de Jacques Lacan (Buenos Aires: Paidós, 1981), 18.

${ }^{2}$ Ibid., 23.

3 Jacques Lacan, "El universo simbólico", en El Seminario. Libro 2. El yo en la teoría de Freud y en la técnica psicoanalítica (Buenos Aires: Paidós, 1978), 37.

${ }^{4}$ Jacques Lacan, "Una definición materialista del fenómeno de conciencia”, en El Seminario. Libro 2, 68.
} 


\section{enn-claves}

posición maestra "distinguido como lugar de la palabra", 5 lugar de donde emerge el mensaje que emite.

Lacan $^{6}$ se interroga sobre cómo se da este reconocimiento del sujeto y su encuentro con el lenguaje; si este yo [je] (mundo simbólico-gramatical) es captado de forma inmediata en el campo de la conciencia o adviene en otro momento, abriendo la pregunta por lo que en este mundo constituye al ser del sujeto. Para ello nos lleva a distinguir el yo [moi] del yo [je] sabiendo que hay una recíproca, es decir, un advenimiento donde imagen y palabra se entrecruzan, donde uno está en función del otro y viceversa.

Para Lacan $^{7}$ este interjuego donde imaginario y simbólico se entrecruzan se inaugura con el estadio del espejo, periodo comprendido entre los 6 y 18 meses de edad, en el que el bebé es capaz de reconocer su imagen en el espejo, precipitando una identificación con una imagen totalizada del cuerpo, a la que accede por otra imagen que se le devuelve desde la exterioridad. Imagen que mira con gozo, pues mientras él desde su cenestesia y desarrollo motriz puede sentirse fragmentado, esa imagen que se devuelve no descortina, le aparece completa; hay una imagen entera que incluso después se le dirá que ése que ve es él; imagen pues de mí, de mi yo, del yo.

Una dialéctica entre lo que se experimenta como imagen desconectada, discordante, fragmentada y la unidad que el otro le devuelve desde fuera, con la cual se confunde y aparea. Es un estado de fascinación donde una imagen está condicionada por la otra. Es decir, que de entrada existe el yo [moi] que se constituye a partir de imágenes que se articulan en relación con un otro que devuelve y enviste de sentido. Un momento de primera identificación en el sentido de la transformación producida en el sujeto cuando asume una imagen, que cumple la función de "antiguo imago". 8

Momento inaugural que unifica al sujeto, pero a su vez lo aliena en una imagen virtual. Un fenómeno de espejismo en que "el yo es desde el inicio por sí mismo otro, porque se instaura en una dualidad interna al sujeto". 9 Por tanto, el llamado estadio del

\footnotetext{
5 Jacques Lacan, "Subversión del sujeto y dialéctica de su deseo en el inconsciente freudiano", en Escritos 2 (México: Siglo XXI, 2001), 786.

${ }^{6}$ Lacan, "Una definición materialista", 77-80.

${ }^{7}$ Jacques Lacan, "Del cosmos al Unheimlichkeit", en El Seminario. Libro 10. La angustia. Los Seminarios de Jacques Lacan (Buenos Aires: Paidós, 2004), 42.

${ }^{8}$ Jacques Lacan, "El estadio del espejo como formador de la función del yo [je] tal como se nos revela en la experiencia psicoanalítica", en Escritos 1 (Buenos Aires, Siglo XXI, 1971), 87.

9 Jacques Lacan, "La disolución imaginaria", en El Seminario. Libro 3, 135.
} 


\section{enn-claves}

espejo se puede comprender como una identificación, el advenimiento de un reconocimiento del sí mismo en el otro Yo es otro. Es en este momento que tenemos, por un lado, la prematuración humana que hace que el infans viva su incoordinación motora confrontada-comparada con una bella forma del cuerpo, visto a partir del garante del Otro que la sostiene.

Lacan $^{10}$ para ello nos lleva a recordar ese movimiento del pequeño, quien volteando hacia atrás parece pedir a quien lo sostiene $-\mathrm{y}$ que representa aquí al Otro con mayúscula - que ratifique el valor de esta imagen. Esta validación marca un vínculo inaugural entre la relación con el Otro y el advenimiento de la imagen especular i(a). Una identificación primaria que, a partir de ese soporte brindado, le permite ir unificando a un cuerpo que desde su desarrollo es sentido como fragmentado, desajustado, en una forma de completud: el yo ideal. Por ello, la imagen especular es la matriz sobre la cual el yo [je] se precipita, en el sentido de que será como imago primordial, también el tronco de las identificaciones secundarias. ${ }^{11}$ De ahí que entre el yo [moi] y el yo [je] se diga que hay una recíproca.

En este interjuego, al hablar de Otro como soporte, se apela a la madre, quien desde el momento de la concepción juega un papel clave, pues desde entonces atribuye al hijo un cuerpo imaginado que, aunque distinto al que tendrá el bebé en el plano real, implica ya la creación de un soporte donde el deseo materno pueda apuntalarse. "Este cuerpo imaginado a partir del cual el niño es interpelado en su ser por la madre, va a ofrecer al sujeto aquel punto de referencia fuera de sí mismo que le permitirá verse como el otro, abriendo una posible entrada hacia la metáfora y el símbolo". ${ }^{2}$

Por ello, Lacan indica que "la función del investimento especular está situada en el interior de la dialéctica del narcisismo tal como Freud la introdujo". ${ }^{13}$ Pues esta i(a) toma como soporte lo que la madre en su papel de cuidadora otorga, enviste y sostiene con su mirada y palabra. Es decir, que, al estar investido por la libido materna, ese objeto codiciable que es su imagen especular se transforma en yo ideal (el objeto del narcisismo

\footnotetext{
${ }^{10}$ Lacan, "Del cosmos al Unheimlichkeit", 42.

${ }^{11}$ Lacan, "El estadio del espejo", 87.

12 Alphonse de Waelhens, "El acceso al lenguaje y la represión primaria. Su fracaso en la psicosis esquizofrénica", en La psicosis: ensayos de interpretación analítica y existencial (Madrid: Morata, 1985$)$ ), 50.

${ }^{13}$ Lacan, "Del cosmos al Unheimlichkeit", 49.
} 


\section{enn-claves}

primario). Así es que el reconocimiento del sujeto acerca de sí mismo debe pasar por el desvío que supone el reconocimiento por parte del Otro.

Es justo esta equivalencia de imagen-objeto narcisista lo que da su carácter de señuelo, pues constituirá la fuente de todas las identificaciones secundarias para el yo, desempeñando el papel de norma "del que tengo que ser... para ser". ${ }^{14}$ La imagen ideal es por tanto lo que permite al niño experimentar una 'mismisidad de ser'. Es decir, una continuidad narcisista o espaciotemporal, una noción de existencia ${ }^{15}$ la cual deberá estar capturada a su vez por la palabra y la red significante. Así el cuerpo imaginario yo [moi] que se unifica anticipadamente en la imagen de Otro -como sede de imagos e identificaciones - pasará a constituirse como un cuerpo significante, donde lo imaginario se reescriba en términos simbólicos.

En este sentido, en el estadio del espejo lo imaginario y simbólico se trenzan donde, entre esa imagen especular y el significante, deberá aparecer un corte. Se tratará, dice Lacan de recordar "cómo la relación especular ocupa su lugar y de qué modo depende del hecho de que el sujeto se constituye en el lugar del Otro y su marca se constituye en relación con el significante". ${ }^{16}$ La imagen queda abierta a la dialéctica para pasar de ser una Gestalt por devenir a una serie de elementos articulados bajo las leyes del lenguaje. Por tanto, la hiancia existente entre la imagen ajena y la que se constituye como propia convoca a algo más que mantenga la relación y ello remite directamente al Edipo. Ahí está el corte que Lacan indica se coloca en medio de esta relación del imaginario con el simbólico, que incide en la estructuración psíquica del sujeto.

Tenemos entonces un primer momento de alienación respecto a la madre, donde el niño está colocado frente a ella en una relación dialéctica imaginaria bajo la forma del ideal del yo, en el lugar de ofrecerse como señuelo para satisfacerla. Un juego tramposo donde percibe el falo como centro del deseo de la madre. La crianza se identifica con él y se sitúa en posiciones por las cuales se ve llevado a sostener esta posición fálica. Para salir de este impasse debe producirse una colisión. Ese choque vendrá dado por el Complejo de Edipo.

\footnotetext{
${ }^{14}$ Waelhens, "El acceso al lenguaje...", 61.

${ }^{15}$ Francoise Dolto, La imagen inconsciente del cuerpo (Barcelona: Paidós, 2003), 43.

${ }^{16}$ Ibid., 42.
} 


\section{enn-claves}

Un padre, no el real, sino el simbólico que pueda enunciar "yo soy padre" interviniendo provisto de un derecho. ${ }^{17}$ Una enunciación que se plantea como dando autoridad a la ley, lo que se articula a nivel del significante. Así, la presencia-enunciación de un padre inaugura un movimiento que muestra al niño que eso que se desea no lo puede tener, verse limitado, regulado; que no hay aparición posible de un sujeto en cuanto tal sino a partir de la introducción primera de un significante y del significante más simple, el que se llama rasgo unario: el Nombre del Padre.

De tal manera, dice $\operatorname{Lacan}^{18}$ al Nombre del Padre hay que tenerlo, pero también hay que servirse de él, como ordenador, como fundamento de la ley. El sujeto y todo lo que de él advenga dependerá de los significantes que se colocan en el grande Otro y lo que ocurra en ese juego. De esta manera, el complejo de Edipo tendrá una función normativa, no simplemente en la estructura moral del sujeto, sino en sus relaciones, en la asunción de su sexo, en la regulación de su goce, en el lugar en el que se cuenta en la cadena; dejando una inscripción de ley como reprimida en el inconsciente, pero permanente donde "el sujeto es así iniciado, por prohibición en la potencia de su deseo". ${ }^{19}$

Con ello se inaugura una relación con el Otro, a quien en un movimiento de invocación puede formular la pregunta ¿che voi? ¿Qué me quiere? ¿Qué pide él de mí? ${ }^{20}$ En este sentido, el Otro concierne al deseo del sujeto, en la medida de lo que le falta. Aparece la barra, marca simbólica inscrita por la represión primaria, con la entrada de un significante que operó como ordenador y que deja a consecuencia un sujeto en falta y la caída de un objeto, el objeto a como lo que queda recortado del cuerpo por inscripción de la ley. El objeto a, por tanto, es el objeto definido como un resto irreductible a la simbolización en el lugar del Otro, de quien depende, "objeto que es el principio que hace desear, que hace al sujeto deseante de una falta". ${ }^{21}$

\footnotetext{
17 Jacques Lacan, "La metáfora paterna", en El Seminario. Libro 5. Las formaciones del inconsciente. Los Seminarios de Jacques Lacan (Buenos Aires: Paidós, 1998), 177.

${ }^{18}$ Jacques Lacan, "La forclusión del Nombre del Padre”, en El Seminario. Libro 5, 150.

${ }^{19}$ Ibid., 65.

${ }^{20}$ Jacques Lacan "La angustia en la red de los significantes" en El Seminario. Libro 10. La angustia. Los Seminarios de Jacques Lacan (Buenos Aires: Paidós, 2004), 14.

${ }^{21}$ Jacques Lacan, "De los Nombres del Padre”, en El Seminario. Libro 10, 358.
} 


\section{enn-claves}

\section{Forclusión del Nombre del Padre. Los desgarros de lo real}

Al final del complejo de Edipo habrá una inscripción de la ley como reprimida en el inconsciente, pero permanente, dejando como núcleo al super yo. El sujeto ha capturado, conquistado el orden significante y con ello se plantea la cuestión de saber cuál es el orden de entrada, de introducción, de instancia presente en el significante. Sin embargo, para el caso de la psicosis, a diferencia de la verdrängung [la represión], en la que la cadena significante sigue desplegándose y ordenándose en el Otro, lo sepa o no el sujeto; en la verwenfung [la forclusión], hay en la cadena de los significantes, un significante o una letra que siempre falta a la tipografía. ${ }^{22}$

Hay una falta de articulación simbólica con los componentes en la estructura del sujeto, en términos del paso a través del complejo de Edipo y la respectiva inscripción del significante paterno en su aparato psíquico. Al quedar forcluído hay, de acuerdo con Lacan, ${ }^{23}$ algo primordial al sujeto que no entra en la cadena, que deja un lugar de desconocimiento y da lugar al retorno en otra dimensión del elemento excluido. Un impasse de perplejidad respecto al significante, como si el sujeto reaccionara frente a ello mediante una tentativa de restitución, de compensación, al no saber responder ante su ausencia.

Impasse que puede presentarse cuando el sujeto es convocado a ejercer alguna de las funciones relacionadas con el significante del Nombre del Padre. Sin estos significantes es el fin del mundo como él lo conoce, momentos que como Lacan señala "amenazan con derrumbar todo el edificio" 24 en la medida en que no puede vincularse con nada ya que no entró nunca el sistema de simbolización. Entonces, lo que regresa de lo real aparece bajo el registro de la significación, una significación que no remite a nada, ya que el anudamiento que debería haber sido ejercido por el Nombre del Padre no se efectuó de la manera correcta.

El psicótico, cuando es confrontado con el agujero, se queda en desconocimiento y da lugar al retorno en otra dimensión de lo que fue excluido. Pasa a ser acosado por un enjambre de significantes que le vuelven desde lo real, de ahí su angustia, tratando de hacer algo con ellos que den más o menos respuesta a ese vacío. De esta manera, el desencadenante de la psicosis se asocia con la percepción de que todo el conocimiento que

\footnotetext{
22 Jacques Lacan, “Introducción a la cuestión de la psicosis", 23.

${ }^{23}$ Jacques Lacan, "El significante en cuanto tal no significa nada", en El Seminario. Libro 3, 272.

${ }^{24}$ Jacques, Lacan, "El fenómeno psicótico y su mecanismo", en El Seminario. Libro 3, 125.
} 


\section{enn-claves}

el sujeto poseía y usó hasta entonces para sostenerse dentro del orden simbólico se ha derrumbado.

Después de esto, el sujeto experimenta un tipo de desencadenamiento. Los dos tipos más comunes de evolución a partir de estos sucesos son: (1) un reordenamiento intenso de la cadena significante que se expresa en neologismos y las estructuras sintácticas peculiares típicas de la psicosis, y (2) la realización de la proliferación o desintegración de lo imaginario: la disolución del yo, cuando el mundo del sujeto parece explotar en miles de fragmentos, perdiendo su consistencia y destruyendo la propia identidad formal del sujeto y la de otros individuos a su alrededor en muchas identidades diversas que son independientes entre sí.

Así, lo que Lacan comprende como la dimensión pura y quebrada del significante pude pensarse como un exceso de goce no regulado, no localizado o localizado de manera atípica, donde por las fallas en la inscripción el nudo borromeo presenta carencias. Lo que la neurosis dialectiza en su relación con el Otro, la psicosis "lo suelta y lo constatamos en fenómenos contrastados de mortificación y goce desenfrenados que se yuxtaponen sin dialéctica un ir y venir desorganizado de fenómenos de negativización y positivización de la vida". 25

Por lo tanto, la psicosis se caracteriza por una desorganización del lenguaje y del pensamiento al no poder ordenarse por un déficit del registro de lo simbólico, por el rechazo de la función paterna. Ordinariamente, cuando un sujeto psicótico mantiene apariencias de normalidad el déficit del registro de lo simbólico está parcialmente compensado por una formación substitutiva, aunque algo precaria; ésta es precisamente lo que Lacan llamó de sinthome: "plantear el lazo enigmático de lo imaginario, lo simbólico y lo real implica o supone la existencia del síntoma". ${ }^{26}$ El sinthome designa en parte el Nombre del Padre, la realidad psíquica o el Edipo. El sinthome definido a partir del nudo borromeo, al cual se le añade como un cuarto lazo, un cuarto redondel agregado al nudo borromeo, que uniría, a manera de pseudo solución lo real, lo imaginario y lo simbólico. Según Lacan, el cuarto anillo es el síntoma del Nombre del Padre, ${ }^{27}$ a propósito de James

\footnotetext{
${ }^{25}$ Ibid., 47.

${ }^{26}$ Jacques, Lacan, "Del uso lógico del sinthome, o Freud con Joyce", en El Seminario. Libro 23. El sinthome. Los seminarios de Jacques Lacan (Buenos Aires: Paidós, 2005), 20.

${ }^{27}$ Lacan, "Del uso lógico", 21.
} 


\section{enn-claves}

Joyce, era su literatura, que sostuvo una caricatura del padre. En la psicosis, la metáfora paterna está forcluída, no está integrada a la cadena significante, consecuentemente, el nudo borromeo presenta fisuras, a las cuales el cuarto redondel viene a suturar, a través del arte. El arte puede sostener el nudo borromeo de cuatro anillos, ya que une lo real, lo simbólico y lo imaginario con lo sinthome. El arte es un sinthome, que puede vincular una estructura psíquica, así como una estructura psicótica sin la presencia de síntomas clínicos llamados positivos para la esquizofrenia.

Lacan argumenta que el Padre es un síntoma y eso significa que el Nombre del Padre también es el padre del nombre, la estructura se mantiene, sin embargo, el sinthome no es menos necesario. ${ }^{28}$ La misión de James Joyce, según Lacan, era defender el Nombre del Padre a través de la literatura. En Ulises hay una especie de caricatura del padre, porque, para que él sobreviva, debe ser apoyado por su obra. Las funciones de la escrita son ocultar y mostrar la verdad del síntoma, ya que a través de él es posible superar lo que impone el síntoma. Como en la psicosis, la función paterna es carente, el sujeto necesita fabricarla para reparar las grietas en su propio nudo y lo puede hacer a través del sinthome.

\section{EI arte como un relato del sujeto}

Desde Freud el psicoanálisis ha influido en la práctica y la crítica del arte, para él las obras de arte son simbólicas, como todas las producciones psíquicas, cuyos contenidos latentes forman acertijos que se debían resolver. De esta manera, leer el arte desde el psicoanálisis es aportar una interlocución y crítica posible, es verlo como una vía comunicativa, como una forma de literatura, es decir, como algo legible. El arte que puede ser leído.

El arte ha sido un instrumento expresivo desde los primeros tiempos de la humanidad. El ser humano siempre ha tenido la necesidad de expresarse a través de símbolos y motivos, hacerse entender sin palabras, dar forma a sus pensamientos y fantasías, dejar sus huellas en la tierra para dejar constancia de su existencia. ${ }^{29}$ Por ello podríamos considerar que una creación de arte, en cualquiera de sus expresiones: pintura, música, cine, escultura, es una narrativa subjetiva. Una ficción de sí mismo, por medio de la

\footnotetext{
${ }^{28}$ Ibid.

${ }^{29}$ María Yiannaka, "La expresión plástica como alternativa de comunicación en pacientes esquizofrénicos: arte, terapia y esquizofrenia” [Tesis] (División Bellas Artes, Universidad Complutense de Madrid, España, 2001), 18-19
} 


\section{enn-claves}

cual, el autor plasma un fragmento de su historia. De esta manera, la obra de arte se convierte en un enigma que de alguna forma se dirige a un otro, "como una respuesta al vacío, a lo invisible, a lo que nadie antes se le ocurrió, a la alegría, el horror". ${ }^{30}$ De modo que la creación artística sería una transfiguración de un lugar común, un lugar inventado, nuevo, matizado por el mundo íntimo de quien lo plasma con un mensaje enigmático.

Lugar inventado, pues sabemos que el dibujo no sólo abarca elementos formales o de técnica, ya que junto a la forma viene el contenido y en él se expresa algo del sujeto en su conjunto. Por ello el dibujo libre favorece la expresión de lo inconsciente. En el arte, como en chistes, sueños y síntomas se puede descubrir un saber inconsciente. La obra artística podrá ser entendida como un reflejo de los conflictos psíquicos; "las técnicas de expresión invitan al inconsciente a manifestarse". ${ }^{31}$ En consecuencia, se puede tomar una obra de arte como un enigma en la búsqueda progresiva de una verdad del artista que lo plasma.

Esta facultad del arte como medio de expresión, apunta a la función sublimatoria introducida por el psicoanálisis. Gracias a ella, Freud considera que el artista, al igual que el niño cuando juega, hace uso de la fantasía, creando un mundo al que dota de afectos al tiempo que lo separa de la realidad efectiva. ${ }^{32}$ De esta manera, "muchas cosas que de ser reales no depararían goce, pueden empero, depararlo en el juego de la fantasía, y muchas excitaciones que en sí mismas son en verdad penosas, pueden convertirse en fuente de satisfacción para el auditorio y los espectadores". Y ahí es donde radica la técnica del artista como una forma de "liberación de las tensiones en el interior del alma". ${ }^{33}$

En este sentido, según Freud es posible captar a través del análisis de las obras de arte la realidad psíquica del artista y el impacto que estas causan en aquellos que las observan. Impacto que no se trata de una captación meramente intelectual, sino que "es preciso que en nosotros se reproduzca la situación afectiva; la constelación psíquica que

\footnotetext{
${ }^{30}$ Carlos Motta, "Psicoanálisis y arte: respuesta al vacío". Virtualia. Revista Psicoanalítica de la EOL, núm. 20 (2010): 2-6, http://www.revistavirtualia.com/articulos/381/arte-de-psicoanalistas/psicoanalisis-y-arterespuesta-al-vacio.

${ }^{31}$ Leandro Palencia Galán, "Las estructuras formales del arte y del psicoanálisis: ¿se puede tumbar el arte al diván? Redalyc, núm. 28 (julio-diciembre, 2008), 30, http://pepsic.bvsalud.org/pdf/aletheia/n28/n28a03.pdf.

32 Sigmund Freud, "El creador literario y el fantaseo", en Obras Completas Tomo IX (Buenos Aires: Amorrortu, 1976), 128.

${ }^{33}$ Ibid., 135.
} 


\section{enn-claves}

prestó al artista la fuerza pulsional para su creación". ${ }^{34}$ Así, sostiene que el propósito del artista no se podría asir con palabras como cualquier otro hecho de la vida anímica, si no se aplica el análisis, pues la obra misma habrá de posibilitarlo "si en verdad es ella la expresión, sobre nosotros eficaz de los propósitos y mociones del artista". ${ }^{35}$

De esta manera, puede pensarse la obra como una manifestación de lo inconsciente que invita a mirar y analizar más allá de la contemplación en sí misma, si bien no como una labor de interpretación sí como una herramienta para pensar los procesos psíquicos acaecidos en el artista, en este caso, padeciendo una enfermedad mental. Es pensar el arte desde su función sublimatoria junto a su concepción como vía de descarga y/o proyección de contenidos inconscientes.

Este enfoque que permitía pensar el arte como vía expresiva dio pie a su vez a las primeras aproximaciones de la actividad artística en relación con la enfermedad mental. En los primeros años del siglo $\mathrm{XX}$, cuando la dementia praecox con su connotación de degeneración irremediable fue reemplazada por el concepto de esquizofrenia, el arte creado por un grupo relativamente pequeño de pacientes psicóticos jugó un papel importante. “Con sus peculiaridades en la forma y en su extraño y a veces impenetrable simbolismo, vinieron a representar, primero para los psiquiatras y luego para el público en general, una imagen de una creatividad trastornada que era a la vez fascinante y amenazadora", ${ }^{36}$ despertando con ello el interés por lo que desde estas creaciones podría ser capturado.

Para Killick y Schaverien, ${ }^{37}$ el arte psicótico, como la psicosis misma, no es un fenómeno fijo y sin cambios, de modo que el interés por los dibujos y creaciones de pacientes psiquiátricos puede verse desde una perspectiva médica, como sintomático, coadyuvando en intentos por medir y diagnosticar la naturaleza de su enfermedad mental; sirviendo así más a fines diagnósticos que terapéuticos y, a la par, ser entendido desde una perspectiva enfocada a sus aspectos creativos y expresivos, donde una creación artística de un psicótico bien puede reflejar su sintomatología y no por ello dejar de ser una vía de expresión.

\footnotetext{
${ }^{34}$ Sigmund Freud, "El Moisés de Miguel Ángel”, en Obras completas Tomo XIII (Buenos Aires: Amorrortu, 1976), 218.

${ }^{35}$ Ibidem.

${ }^{36}$ Katherine Killick y Joy Schaverien, Art, Psychotherapy and Psychosis (Nueva York: Psychology Press: 1997), 131.

${ }^{37}$ Ibid., 132.
} 


\section{enn-claves}

Vía de expresión que, si bien para el campo de la psicosis no podemos hablar de proyección, sí podemos apuntar a la labor creadora del artista como un reflejo de sus conflictos inconscientes y como vía comunicativa, como un saber hacer. No deja de ser un relato subjetivo, sólo que apunta a un fenómeno distinto. Además de que el arte se pueda constituir como una forma de sublimación de las pulsiones, podemos considerarlo como manifestación pictórica del inconsciente, más allá de la representación, pero contemplando los desgarros de lo real.

Para dicha aproximación, la tesis de Lacan de que "todo arte se caracteriza, en suma, por una cierta manera, un cierto modo de organización alrededor de un vacío", y que aquello creado en este registro "será siempre de algún modo representada por un vacío precisamente porque no puede ser representada por otra cosa". ${ }^{38} \mathrm{O}$, más exactamente, que sólo puede ser representada por "otra cosa" nos parece central pues nos permite colocar el arte como práctica que, al igual que el psicoanálisis, bordea el vacío, circunscribiéndolo. El arte como ese cuarto elemento, Lacan, en su seminario sobre el síntoma, lo planteaba como necesario para mantener los tres registros unidos.

En el seminario 24, Lacan articula que el arte es un saber hacer más allá de lo simbólico, es un know-how que dibuja, escribe e inscribe el sujeto. El arte es una creación que puede sostener el nudo borromeo. El arte es un verbo en la segunda potencia, que une el lenguaje y mantiene la psique unida. Por lo tanto, el trabajo artístico tiene el poder de mantener un sujeto del lenguaje que sabe cómo hacerlo y conserva el nudo borromeo amarrado. El arte puede ser el cuarto anillo que podría estar más allá de lo simbólico, como aquello que viene a anudar lo que queda suelto en la conformación psíquica del artista.

Nos apoyamos para ello en el esquema de la 'cuatrenza' planteado por Lacan, que es una tesitura de lo real, imaginario, sinthome y simbólico. Desde este modelo el arte puede dar cuenta de las posibles rasgaduras en la trenza. Estos desgarrones son como agujeros vacíos que no pueden representarse. Lo real incidiendo, principalmente sobre el cuerpo, en relación con lo imaginario; hasta donde entre lo simbólico. Para él, el arte es un saber hacer con eso que queda suelto: "Trato de decir que el arte está más allá de lo

\footnotetext{
${ }^{38}$ Jacques Lacan, "Breves comentarios al margen”, en Seminario 7. La ética del psicoanálisis (Buenos Aires: Blibliopsi, 1960), 68.
} 


\section{enn-claves}

simbólico. El arte es un saber-hacer, lo simbólico está en el principio del hacer. Creo que hay más verdad en el decir que es el arte que en cualquier bla-bla-bla". 39

Por lo tanto, el arte no evita ni obtura, sino que sirve para organizar el vacío, el desgarro, posibilitando su encuentro con lo real, con lo que excede la palabra pero que deja huella y permite una pregunta. En este sentido, la capacidad de producir ese encuentro tiene que ver con lo que Lacan llama función de cuadro, función en la cual el sujeto ha de localizarse como tal. La pintura como aquello donde el centro es la mirada.

"En el cuadro, dicen unos, el artista quiere ser sujeto y el arte de la pintura se distingue de todos los demás por el hecho de que, en la obra, el propósito del artista es imponerse a nosotros como sujeto, como mirada". ${ }^{40}$ Porque en la obra, como cuadro, el artista se nos muestra para que posemos sobre él una mirada. Asunto que, Lacan nos recuerda, remite al campo escópico inaugural para el sujeto, donde la mirada está afuera, "soy mirado, es decir, soy cuadro". Función que se encuentra en lo más íntimo de la constitución del sujeto, porque la mirada que está fuera lo determina intrínsecamente.

De este modo, el arte es siempre intersubjetivo, en el sentido de que su manifestación no implica sólo al creador, sino también a quién contempla su obra; que el fenómeno estético, al igual que la palabra, no puede sino capturarse desde el otro, quien ubica el objeto creado como a un texto en un contexto, es decir, en el devenir en el cual ese fenómeno emerge y se inserta. Por esto, podemos pensar que la obra encierra un mensaje del artista dirigido a otro.

\section{Él se hizo gato: la esquizofrenia y los desgarros de lo real}

Louis Wain (1860-1939) fue uno de los ilustradores más reconocidos de la época victoriana en Inglaterra; destaca entre su obra la ilustración de gatos antropomorfizados. Hoy en día su obra sigue siendo objeto de interés, no sólo por su afición por estos animales, sino porque se le diagnosticó con esquizofrenia, lo que para algunos se ve reflejada en sus pinturas, siendo las últimas de ellas prueba de su deterioro por esta afección psicótica.

\footnotetext{
39 Jacques Lacan "Lo real continua en lo imaginario" en Seminario 24. La ignorancia que sabe de la una equivocación (se va a la morra) (Buenos Aires: Bibliopsi, 1977), 14.

${ }^{40}$ Jacques Lacan, “¿Qué es un cuadro?”, en El Seminario. Libro 11. Los cuatro conceptos fundamentales del psicoanálisis. Los Seminarios de Jacques Lacan (Argentina: Paidós, 1964), 107.

${ }^{41}$ Ibid., 113.
} 


\section{enn-claves}

Wain nació el 5 de agosto de 1860, en Clerkenwell, Londres. Su familia estaba conformada por sus padres y cinco hermanas, siendo él el mayor y único varón. En 1877 ingresó a la escuela de artes West London, de la cual fue profesor por un breve periodo de tiempo. A sus 20 años fallece su padre; para poder solventar sus gastos comenzó a trabajar como ilustrador para revistas, ${ }^{42}$ oficio al que terminó por dedicarse completamente. En este primer periodo de su obra se enfocó en bosquejos naturalistas, escenas de campo y paisajes.

En 1884 contrajo matrimonio con una mujer 10 años mayor que él, quien después de tres años de casados falleció de cáncer. Durante este periodo, se dice que Wain comenzó a realizar dibujos de su gato Peter, con la intención de animar a su esposa enferma, quien a su vez lo instó a publicarlos, y así comenzaron las primeras publicaciones de gatos antropomorfizados de Wain. ${ }^{43}$

Durante los próximos 30 años, Louis Wain fue reconocido como un artista prolífico, continuando su obra, apareciendo en diversas publicaciones, libros, periódicos y revistas. En la década de 1900, fue un colaborador continuo de los medios impresos de Inglaterra; en promedio, produjo 600 nuevos diseños por año. A lo largo de su vida ilustró más de 200 libros y tuvo 16 calendarios postales navideños de gran aceptación entre la población.

A sus 54 años incursionó haciendo obras de gatos en cerámica, que fueron muy bien acogidos en Estados unidos. Éste fue su último trabajo exitoso. Su carácter, antes agradable, se tornó agresivo y desconfiado. En 1924, a los 64 años se le internó en el Hospital Mental Springfield, en Tooting; un año más tarde, fue trasladado al Hospital Real de Bethlem en Southwark, y en 1930, de nuevo al Napsbury Hospital, donde estuvo hasta su muerte, en 1939. Durante estos periodos de internación, Louis Wain continuó pintando obras de gatos, muchas de las cuales hoy en día se encuentran como parte de las obras en el museo que auspicia el hospital de Bethlem en Inglaterra. ${ }^{44}$

Como señalan Killick y Schaverien, ${ }^{45}$ una de las maneras de acercarse al arte de Wain es considerándolo una ventana directa a su mente, a su mundo interno, donde usando

\footnotetext{
${ }^{42}$ Aiden McGennis, "Louis Wain. His Life, his Art and his Mental Illnes". Irish Journal of Psychological Medicine 16, núm. 1 (2014): 1-2. https://www.cambridge.org/core/journals/irish-journal-of-psychologicalmedicine/article/louis-wain-his-life-his-art-and-his-mentalillness/E139F387B2D2D32189F52D521CB7CF60.

${ }^{43}$ Philip Kennedy, "Cute cats en psychedelis: The tragic life of Louis Wain". En Illustration Chronicles 175 years, 175 stories.

${ }^{44}$ Ibidem.

${ }^{45}$ Killick y Schaverien, “Art, Psychotherapy and Psychosis”, 135.
} 


\section{enn-claves}

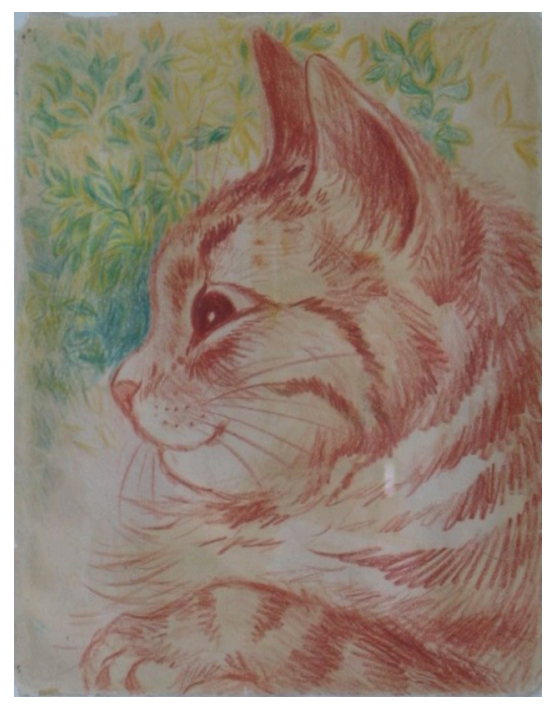

Fig 1. Louis Wain. Kaleidoscope Cat. Derechos de autor: Bethlem Museum of the Mind, Londres.

una serie no fechada pero progresiva de sus obras, se puede ilustrar su progresiva desintegración. Permitiéndonos analizar el desarrollo de sus obras, encontramos que su primer periodo como artista, cuando la enfermedad aun no irrumpía, sus pinturas tienen trazos claros, bien definidos y de un estilo naturalista. En las pinturas de esta época Wain hacía una representación de la realidad acorde a los estándares dando cuenta de su técnica y habilidad para el dibujo.

Estas pinturas son prueba de cómo el esquizofrénico, previo al desencadenamiento, de una u otra manera, se las arregla para funcionar por el mundo. Un periodo en el que Wain comenzaba su vida como artista, recién egresado de la escuela de artes, donde pareciera el mundo escolar y profesional ofrecían un sostén para su funcionamiento. Dicho reconocimiento pudiera haber cumplido por entonces la función de soporte, que venía de la identificación con la que imagen que de él se iban haciendo los demás, alrededor de la cual se organizaba.

Así, tomará las imágenes que los otros le aportan para buscar sostenerse, pero lo hará solamente de manera ilusoria, de una identificación como tal que le resulta imposible. Pues como sabemos es la entrada del primer significante el que ordena la dimensión imaginaria, el que abre el juego de las identificaciones y reconocimientos futuros, que le brinda al sujeto la cohesión de su yo. Cohesión que en el esquizofrénico no se logra.

En este sentido, es interesante cómo Wain elige al gato como elemento central de su obra. El gato cargado de sentido en tanto referente del vínculo de Wain con su esposa, del amor, del cuidado y así mismo de un medio para hacerla sentir feliz. Así nos vemos llevados a pensar que, en algún momento de su trayectoria, el gato pasó de ser la imagen base de sus obras para convertirse en ese semblante en el que el mundo interior de Wain era expresado. Un gato de inicio ligado a su mascota Peter, pero que poco a poco en el avance de su enfermedad cobra sus vivencias psicóticas. 


\section{enn-claves}

De esta manera, el gato como semblante de sí mismo y el lienzo como espejo pone en evidencia lo que desarrollamos respecto al primer tiempo de la conformación yoica en la que hacíamos ver cómo la imagen propia como imagen discordante y fragmentada se confunde y aparea con la imagen el espejo en una unidad alienada y virtual. En esta dialéctica, Wain queda suspendido en la imagen del gato sobre el lienzo, en la medida en que éste le proporciona un modelo, su modelo en ese estado fundante de fascinación.

Primer momento de la conformación yoica en la que el psicótico queda atrapado en el que el Yo es otro. Yo es el gato. Yo es gato. Es convocar a ese tiempo en el que el sujeto capturado en esa unidad alienada y virtual de la imagen que le viene de fuera está fijado en una relación imaginaria, de espejismo. El gato

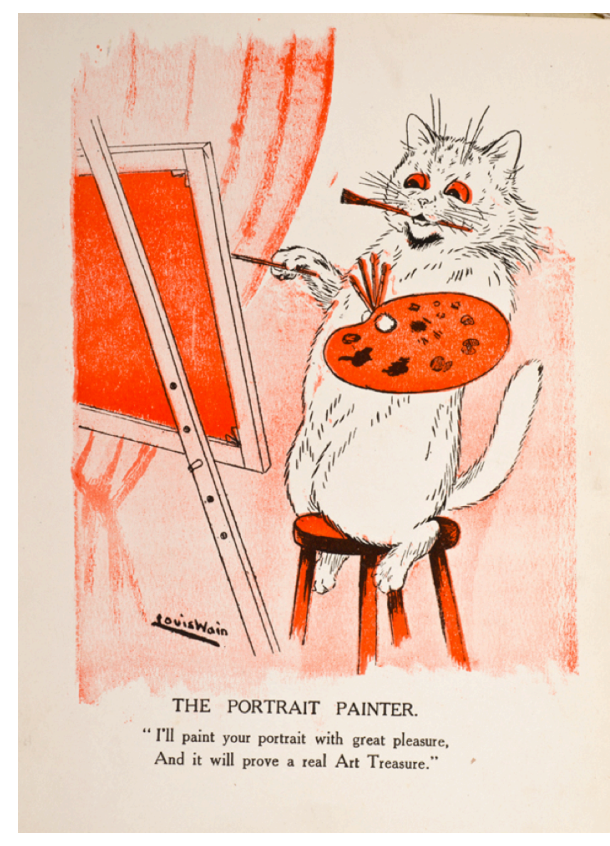

Fig 2. Louis Wain. The Portrait Painter. The Nursery Land with Louis Wain. Derechos de autor: David Brass Rare Books. y el artista, el sí mismo y el otro, que son reciprocables sin cesar: el que ve se ve. El portrait painter que se pinta, y se encuentra en su pintura; un quedar atrapado en ese estadio especular, donde la identificación —el advenimiento de un reconocimiento del sí mismo- está en el otro.

Por la falla en la inscripción significante el lugar del otro/Otro queda alterado, por lo cual el sujeto no accede como tal al orden de su genealogía, de su estar en el mundo. Un yo que queda capturado en el transitivismo del 'otro soy yo' como imposibilidad de una separación entre el yo y el no yo en la constitución de la unidad y la imagen corporal del sujeto. Un conocimiento sobre sí mismo que permanece sin contornos bien establecidos y que regresa de una manera desbordante y aterradora, frente a la cual el esquizofrénico no encuentra cómo delimitar y reordenar lo que ha quedado fuera.

Espejismo en el que nuestro artista queda atrapado bajo la lógica de que el otro que él es está allí, fuera de sí, donde primero se ha visto formar su ego. Quedando así capturado 


\section{enn-claves}

en esa relación virtual. De este modo podemos pensar al gato a lo largo de las pinturas de Wain como esa imagen inaugural con la que el artista se confunde y se aparea, en una relación virtual, donde el lienzo cumple la función de espejo.

No obstante — tomando en cuenta que la

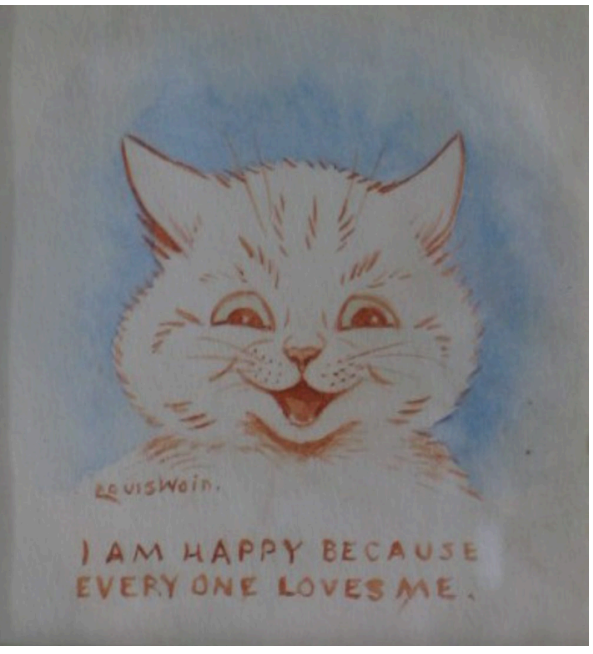

Fig 3. Louis Wain. [I'm happy because everyone loves me]. Derechos de autor: Bethlem Museum of the Mind, Londres. función del investimento especular está situada en el interior de la dialéctica de narcisismo y presupone el desvío por el reconocimiento fundado en la palabra y la red significante-, en el caso de la psicosis, tarde o temprano, esa mismisidad aparente comienza a fracturarse. De esta forma las ilustraciones de Wain empiezan a tomar rasgos particulares, las pinturas muestran más de sí. En ellas vemos un manejo más vivo y libre de los colores. Los trazos comienzan a ser menos rígidos y las expresiones de los gatos poco a poco se van desnaturalizando para mostrarlos caricaturizados, con gestos y muecas que los hacen aparecer como simpáticos, juguetones y accesibles.

En su dibujo podemos ver el mensaje "estoy feliz porque todos me aman" y guiños en la mirada, que nos hacen pensar en ese momento de la vida de Wain, donde —rodeado de éxito y una vida de casado- podría mostrarse accesible. Sabemos que sus primeras obras fueron recibidas gratamente por el público, y que colaboraba activamente con las revistas y periódicos de su época. Un momento de estabilidad dentro de la enfermedad.

No obstante, con el paso del tiempo, acorde a los datos de su biografía, comienzan a aparecer señales de alerta en su comportamiento: se muestra aislado, errático e impulsivo, como una señal del inicio del irrumpimiento de su enfermedad. De modo que vemos a un sujeto presa de la angustia a causa de un replegamiento del mundo que lo fuerza a recrear la realidad, y a causa de la falta de inscripción significante que dé entrada a la palabra como pacto ordenador de lo que a cada uno le corresponde. 


\section{enn-claves}

El sujeto, delante de eso, se encuentra un impasse de perplejidad. Impasse que acarrea el sujeto en los momentos en que es convocado a ejercer alguna de las funciones relacionadas con el significante del Nombre del Padre. Delante del agujero que se abre por la falta de esa inscripción aparece la angustia como respuesta a esa ausencia.

Wain tuvo situaciones críticas en su vida que nos llevan a pensar que pudieron de alguna manera confrontar con este agujero: la muerte del padre, la muerte de la esposa, el llamado a hacerse cargo de la familia, la vuelta a la casa materna; comenzando a fracturarle y de a poco hacer percibir el mundo circundante con estupefacción y alerta, como podemos ir viendo en la gradual transformación de sus ilustraciones, poniendo énfasis en la mirada de sus gatos, que comienza a aparecer alerta, como si estuviera pendiente de algo o de alguien.

Para Lacan este desencadenamiento sería justamente cuando algo que podría parecer una nadería "amenaza con derrumbar todo el edificio". Que el esquizofrénico cuando es confrontado con el agujero se queda en desconocimiento y da lugar al retorno en otra dimensión de lo que fue excluido.
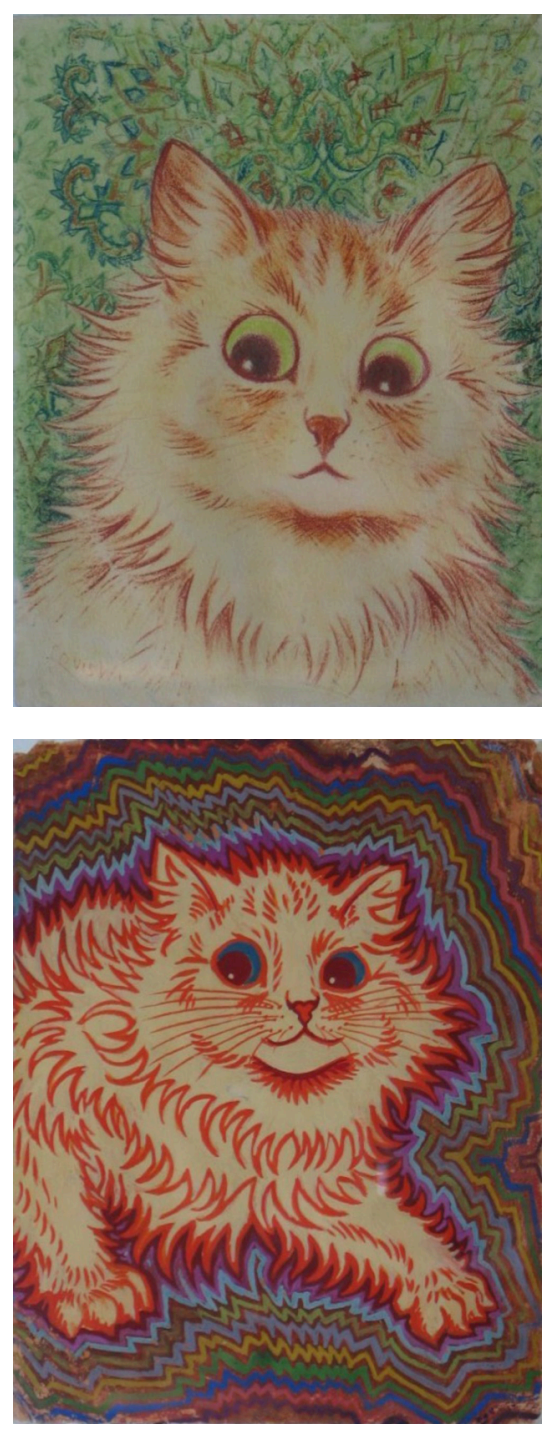

Fig 4. Louis Wain. [Gatos en alerta] Derechos de autor: Bethlem Museum of the Mind, Londres. ¿Cómo responder al vacío cuando la dialéctica con el Otro está alterada? Si para Lacan la relación del sujeto con el significante es lo que permite responder a las preguntas ¿qué quiere el otro de mí? ¿Qué me pide él a mí? En tanto mediador del deseo, podemos pensar este gato estupefacto como un sujeto suspendido frente a una pregunta respecto de sí que no puede responder.

\footnotetext{
${ }^{46}$ Lacan, "El fenómeno psicótico", 124.
} 


\section{enn-claves}

De modo que el sujeto al no poder reestablecer su pacto con el otro, como sede del mensaje, como lugar del código, por no poder realizar mediación simbólica alguna entre lo nuevo y él mismo, entra — como señala $\operatorname{Lacan}^{47}$ - en otro modo de mediación, completamente diferente del primero, que

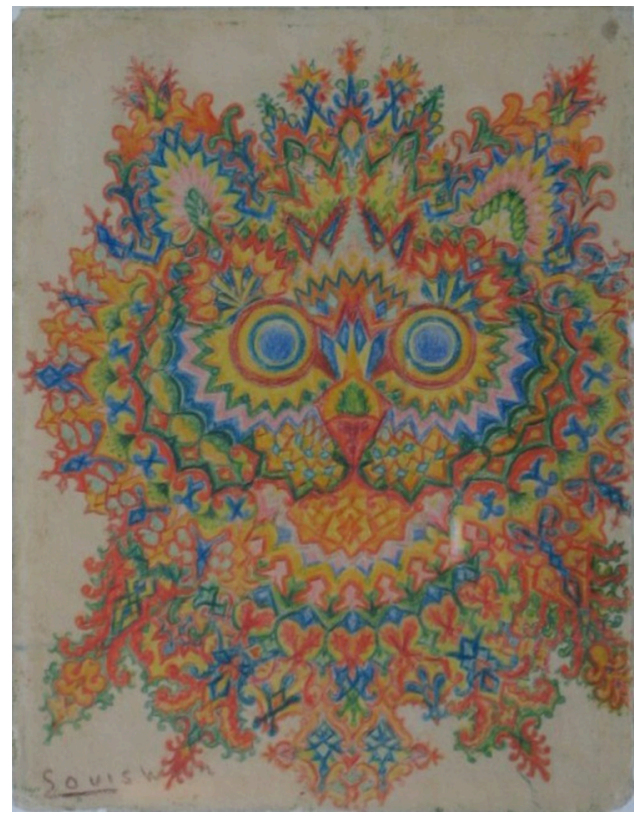

Fig. 5 Louis Wain. Kaleidoscope cats IV. Derechos de autor: Bethlem Museum of the Mind, Londres. sustituye la mediación simbólica por un pulular, una proliferación imaginaria. Proliferación que vemos nuevamente reflejada en sus pinturas subsecuentes. Observamos cómo los límites de la figura del gato comienzan poco a poco a desdibujarse.

Formas intrincadas que consideramos dan cuenta del cómo poco a poco al estar la relación simbólica alterada, con agujeros en la cadena, se acarrea una confusión del plano imaginario, sobre el cual el real incide sus efectos. Podemos observar cómo la figura del gato comienza a perder unicidad, para constituirse por la suma de patrones repetitivos, pequeñas formas que insisten $\mathrm{y}$ que van dando la sensación de un todo, pero fragmentado. Colores, trazos que confluyen, donde formas geométricas aparecen como centrales, con una espontaneidad y creatividad que mucho se aleja de sus primeras obras.

${ }^{47}$ Ibid., 127. 


\section{en-claves}

Al punto que el cuerpo del psicótico cae en un caos imaginario que adviene por la falla de la palabra y los juegos que se hacen con ella donde el sujeto exacerba las sensaciones y alucina con ellas, o que es incapaz de registrarlas porque no disponen de significantes que lo representen. Ley y lenguaje van indiscutiblemente ligados, y cuando algo de ese lenguaje, en tanto entrada a lo simbólico, falla el órgano, el cuerpo va a ponerse a hablar bajo el efecto del trabajo del delirio.

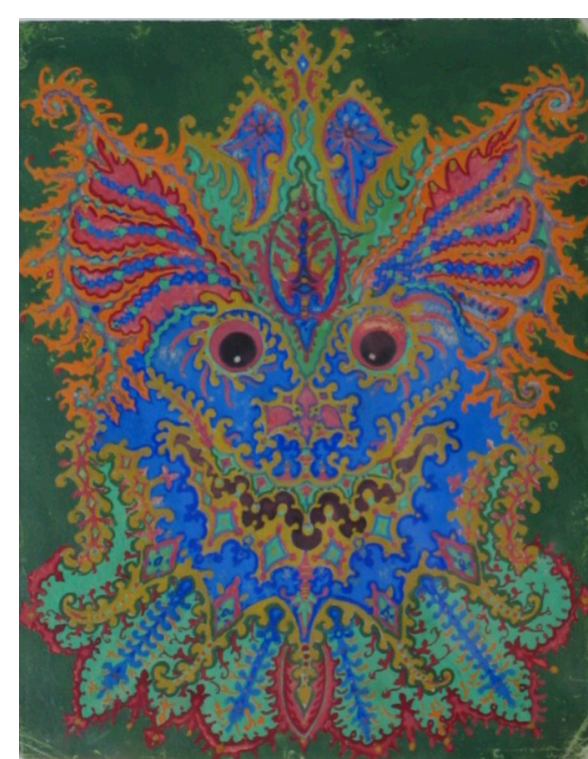

Fig 6. Louis Wain. Kaleidoscope cats V. Derechos de autor: Bethlem Museum of the Mind. Londres.

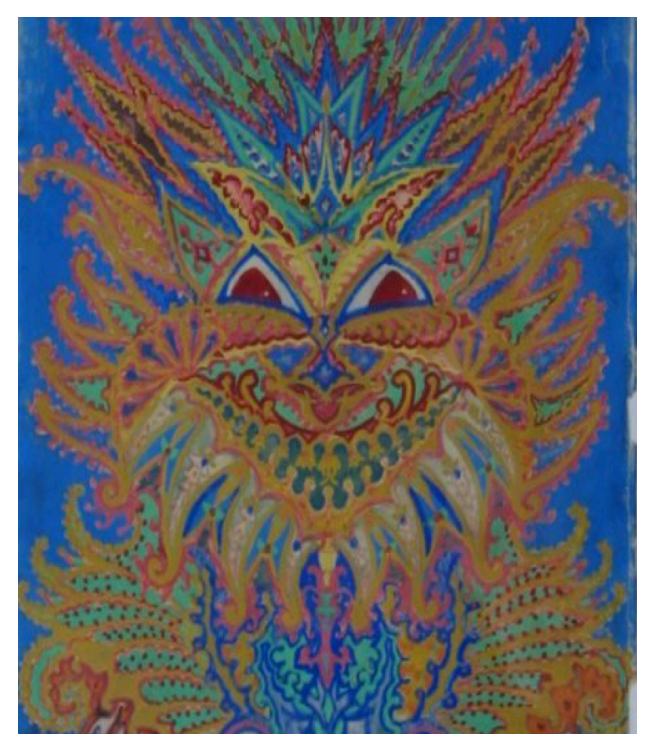

Fig 7. Louis Wain. Kaleidoscope Cats VI.

Derechos de autor: Bethlem Museum of the Mind, Londres.
Esto quiere decir que al no entrar la inscripción significante como reguladora, donde el otro hace ley, no se genera la hiancia de estructura del inconsciente que permite que se separe en el plano sexual el deseo del lugar del goce del otro. Es consecuencia, al no haber intervalo en la cadena que dejaba en suspenso una pregunta para el sujeto, puede advenir un saber todo, un exceso de goce, no regulado, no localizado o localizado de manera atípica, dando como consecuencia una diversidad de objetos fragmentados. 


\section{enn-claves}

Imagen no cohesionada, esto es lo que podemos observar en las últimas obras, donde comprendemos, la figura del gato se ha desdibujado porque denota este exceso que desborda al sujeto, quien al no poder acceder a una representación virtual, unificada, queda a fragmentos. Avance progresivo de la enfermedad que el artista nos muestra en sus pinturas.

La figura va perdiendo unicidad para irse perdiendo en una combinatoria de colores, en un estilo más intrincado y como mencionamos, apuntando a lo que podría considerarse un arte psicodélico en el sentido de sus características: patrones fractales, caleidoscópicos, de colores brillantes, con estilización en los detalles. Mutación de patrones y objetos que incluso transmiten la sensación de un collage contrastante, en el sentido también de cómo el esquizofrénico arma una imagen de sí, como un conglomerado de pedacitos, de piezas, como un lugar desordenado.

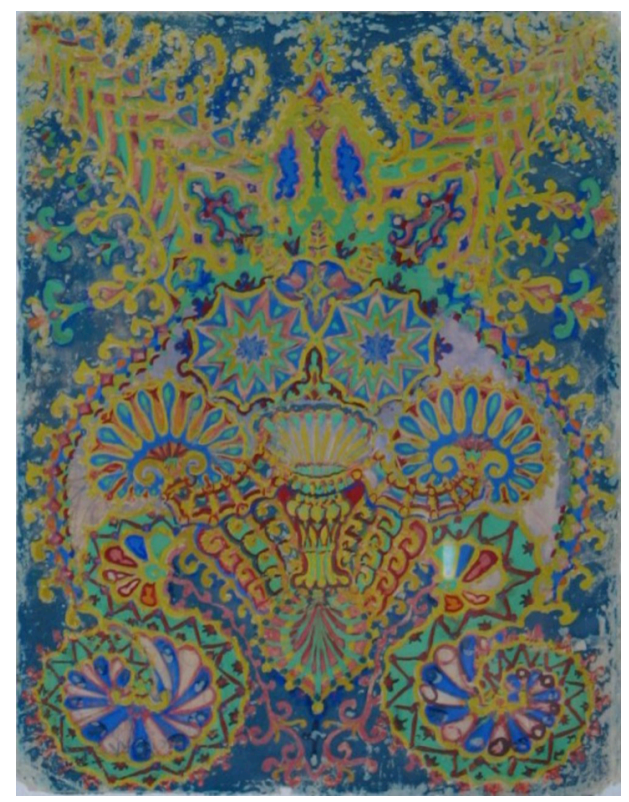

Figura 8. Louis Wain. Kaleidoscope Cats VII. Derechos de autor: Bethlem Museum of the mind. Londres

Collage psicodélico; lugar desordenado que seguramente deja al esquizofrénico con una sensación mortificante, que se ve reflejada en su obra. ¿No es acaso algo de esta sensación mortífera la que podría pesquisarse en este cuadro? (Figura 6). Ya no hay más miradas tiernas y juguetonas, la pintura parece transmitir no sólo el impasse de perplejidad de sus anteriores obras, sino, además, una mirada con una fuerza distinta, quizá reflejo de ese temor, de esa sensación de despersonalización psicótica.

Dimensión quebrada, desintegración yoica, pérdida de unicidad. Un gato difuminado en formas superpuestas, garigoleadas y coloridas. La imagen base se ha desdibujado para mostrar una serie de figuras caleidoscópicas que no transmiten la idea de unidad en sí misma, sino un conglomerado de color que pareciera incluso pudiera salirse de 


\section{enn-claves}

los contornos. Si el lienzo es el espejo, es un espejo que nos muestra un imaginario sobre el que el real ha ejercido su efecto, desdibujando sus bordes, intrincando sus contornos.

Dificultad para reconocer los límites, donde las partes aparecen desorganizadas, intercambiables. Que donde la imagen cohesionada por introducción del Otro está ausente,

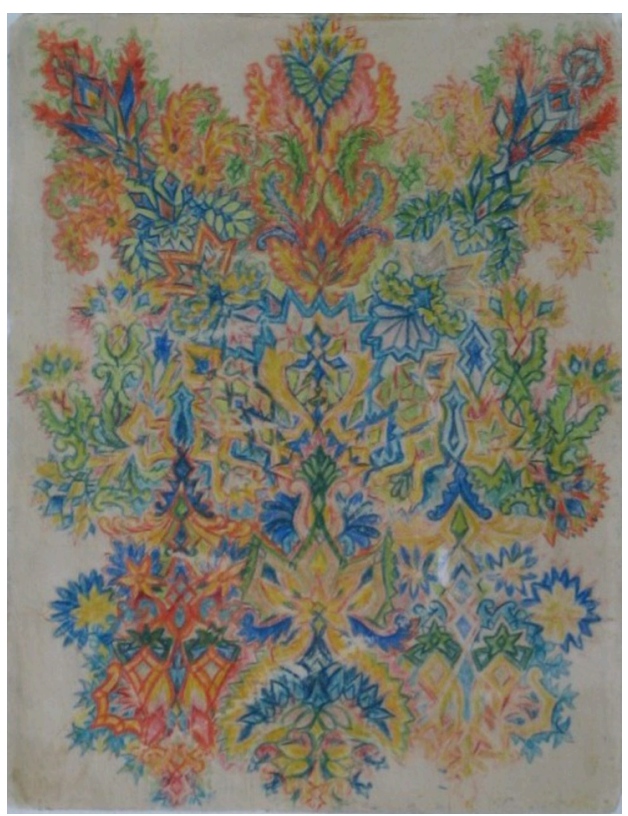

Figura 9. Louis Wain. Kaleidoscope Cats VIII. Derechos de autor: Bethlem Museum of the Mind, Londres.

lo que aparece es una imagen tal como es un plano de la realidad: un conjunto de carne huesos, órganos como un ensamble fisiológico, Gestalt por devenir. Un cuerpo aún en la confusión de lo no capturado por la red simbólica. Confusión y desintegración que, siguiendo nuestra hipótesis del arte como vía de expresión, pudo haber ayudado a su vez como señala Motta a alejar de lo inquietante, de lo siniestro, o al menos, provocar "un intento de mantener a distancia el horror de aquello que resulta difícil de comunicar". 48

Un poner distancia que consideramos tuvo además un efecto pacificador, pues una vez internado en los hospitales psiquiátricos, donde se le permitía pintar libremente, se le describe con un comportamiento tranquilo y pintando de manera continua. Pinturas que dejan ver los jirones, los desgarros en la cuatrenza, cuando se afloja el tejido — por decir de alguno modo - de lo imaginario, real, simbólico y síntoma. Jirones que, como observamos en esta última pintura (Figura 9), parecieran en verdad muestran una forma que se ha aflojado, suelta, sin la sensación de estar pegada, cohesionada entre sí.

Una pintura que podría considerarse como abstracta, donde siendo ella el espejo, nos muestra un déficit de integración. Un cuerpo donde lo real, lo excluido, lo no recortado, es problematizado, expuesto en una expresión creativa.

\footnotetext{
${ }^{48}$ Motta, "Psicoanálisis y arte", 5.
} 


\section{enn-claves}

El arte entonces como un saber hacer con lo que queda suelto que consideramos claramente se ve reflejado en esta imagen donde la pérdida de sus contornos se vio transformada en embrollos geométricos, un goce desbordado que encontró su expresión en el desborde artístico de colores y formas.

\section{Conclusión}

Podemos decir que la falla en la inscripción significante es medular. Sin la entrada del significante del Nombre del Padre y el ideal del yo que adviene como consecuencia del complejo de Edipo, el cuerpo no deviene corporal. No queda capturado, localizado ni regulado por su relación con otro/Otro. Falla inaugural que impide que el yo, que parte de una superficie de percepción y de una imagen que viene de fuera, pueda unificarse. El sujeto queda en un impasse que le impide enunciar éste es mi cuerpo, éste soy yo.

El papel de lo que se ha forcluído deja un vacío de significación, el sujeto, al no poder constituirse como cociente, quiebra la hiancia que supone la dialéctica del deseo, falla que incide directamente en la conformación corporal al impedir la organización del cuerpo como cohesionado. Dicha falla en la estructura deja al sujeto cautivo de una imagen desbordante y sin palabras que le representen. Imagen desbordante por efecto de aquello que quedó fuera del campo de la palabra, que concluimos sí puede ser ubicada en la tela, donde el lienzo, la obra de este artista, aparece como esa búsqueda de localización de aquello que escapa a un decir. Un real que avanza en el cuerpo y se ve plasmado en la tela.

Siendo así, el arte si constituyó una herramienta de acceso al mundo psíquico del sujeto, desde donde nuestra lectura evidencia el efecto de lo no anudado que desgarra el registro de lo imaginario. Consideramos que está probada la tesis lacaniana del arte como acto, en tanto la obra de Wain fue un saber hacer. Un hacer que desde el psicoanálisis deja ver la postura activa del sujeto que se encuentra no en lo que dice, sino en lo que plasma. Los gatos de Wain, como cuadros, como ese marco donde el sujeto nos convoca y nos permitió encontrarle de algún modo. Dibujos y desdibujos que plasman lo que el cuerpo grita cuando el sujeto muda. Lo que desde el inicio Freud pesquisó como central en las formaciones del inconsciente, un cuerpo que conlleva un mensaje.

Así, la imagen - la pintura creada - convoca, nos convoca. Entendiendo esto, podemos colocar el trabajo de los últimos años de Wain bajo la mirada de lo que ahora se 


\section{enn-claves}

conoce como art brut, "el arte que viene de los márgenes", es decir, creaciones que se producen fuera de lo que es considerada la norma, por personas que padecen de alguna enfermedad mental, principalmente la esquizofrenia.

Si bien Wain sí contaba con formación académica, sus dibujos comenzaron a mostrar la progresión de su enfermedad, característico del art brut, pues una vez liberado de las convenciones normales, terminó siendo extrañamente revolucionario. Algunos creen que su obra se adelantó a lo que después se conoció como arte fractal o psicodélico, cualidades de su dibujo que para nosotros evidencian la desintegración de su imagen, la percepción de un mundo desorganizado, no articulado.

La pintura aparece facilitando la expresión por medio de imágenes, de aquello que escapa a la palabra, o que no puede ser aprehendido por ella. Al punto que, cuando Wain crea y deja de imitar la realidad circundante — de representarla imprimiendo su técnica bajo un carácter naturalista - nos brinda un material de interés, pues con su obra de los gatos refleja no sólo lo que ve, sino cómo lo concibe, con imágenes que no corresponden ya a un modelo que recrea, sino que crea. Muestra y comunica con sus gatos antropomorfizados su particularidad como artista, el gato como referente de sí.

Nos vemos llevados a sostener que al arte entonces, más allá de los posibles llamados efectos terapéuticos es un medio de saber hacer más allá del simbólico y quizá podríamos aludir este efecto en relación la obra pictórica de Louis Wain. Es un saber-hacer que dibuja, escribe e inscribe el sujeto. La obra pictórica de Wain hizo sinthome, un sinthome que habilitó un nudo borromeo de cuatro anillos a través de su arte. El arte permitió hacer el nudo, una invención, creación que sostuvo el sujeto. Por lo tanto, concluimos así que sus lienzos le posibilitaron poner distancia de por medio con aquello que le mortificaba, que avasallaba a su yo y a su vez como espejo nos permitió mirar lo que el sujeto alcanza a plasmar respecto a su imagen corporal.

En ese sentido, defendemos la utilidad de la expresión artística como medio para acceder al sujeto, reconocer aspectos de su sintomatología y sobre todo permitirnos un material para seguir aportando lecturas, aportes y reflexiones desde el marco psicoanalítico. 


\section{enn-claves}

\section{Bibliografía}

Dolto, Francoise. La imagen inconsciente del cuerpo. Psicología Profunda. Barcelona: Paidós, 2003.

Freud, Sigmund. "El creador literario y el fantaseo". En Obras Completas Tomo IX. Buenos Aires: Amorrortu, 1976.

Freud, Sigmund. “El Moisés de Miguel Ángel”. En Obras Competas Tomo XIII. Buenos Aires: Amorrortu, 1976.

Kennedy, Philip. "Cute cats en psychedelis: The tragic life of Louis Wain". Illustration Chronicles 175 years, 175 stories (2016). http://illustrationchronicles.com/CuteCats-and-Psychedelia-The-Tragic-Life-of-Louis-Wain.

Killick, Katherine, y Joy Schaverien. Art, Psychotherapy and Psychosis. Nueva York: Psychology Press, 1997.

Lacan, Jacques. "Breves comentarios al margen". En Seminario 7. La ética del psicoanálisis. Buenos Aires: Bibliopsi, 1960.

Lacan, Jacques. "El estadio del espejo como formador de la función del yo [je] tal como se nos revela en la experiencia psicoanalítica". En Escritos 1. Buenos Aires: Siglo XXI, 1971.

Lacan, Jacques. "Lo real continua en lo imaginario". En Seminario 24 La ignorancia que sabe de la una equivocación (se va a la morra). Buenos Aires: Bibliopsi, 1977.

Lacan, Jacques. "El universo simbólico". En El Seminario. Libro 2. El yo en la teoría de Freud y en la técnica psicoanalítica. Los Seminarios de Jacques Lacan. Buenos Aires: Paidós, 1978.

Lacan, Jacques. "Una definición materialista del fenómeno de conciencia". En El Seminario. Libro 2. El yo en la teoría de Freud y en la técnica psicoanalítica. Los Seminarios de Jacques Lacan. Buenos Aires: Paidós, 1978.

Lacan, Jacques. "Introducción a la cuestión de la psicosis". En El Seminario. Libro 3. Las psicosis. Los Seminarios de Jacques Lacan. Buenos Aires: Paidós, 1981.

Lacan, Jacques. "El Otro y la psicosis". En El Seminario. Libro 3. Las psicosis. Los Seminarios de Jacques Lacan. Buenos Aires: Paidós, 1981.

Lacan, Jacques. "La disolución imaginaria". En El Seminario. Libro 3. Las psicosis. Los Seminarios de Jacques Lacan. Buenos Aires: Paidós, 1981. 
Lacan, Jacques. "El fenómeno psicótico y su mecanismo". En El Seminario. Libro 3. Las psicosis. Los Seminarios de Jacques Lacan. Buenos Aires: Paidós, 1981.

Lacan, Jacques. "El significante en cuanto tal no significa nada". En El Seminario. Libro 3. Las psicosis. Los Seminarios de Jacques Lacan. Buenos Aires: Paidós, 1981.

Lacan, Jacques. "La Forclusión del Nombre del Padre". En El Seminario. Libro 5. Las formaciones del inconsciente. Buenos Aires: Paidós, 1998.

Lacan, Jacques. "La metáfora paterna”. En El Seminario. Libro 5. Las formaciones del inconsciente. Buenos Aires: Paidós, 1998.

Lacan, Jacques. "Subversión del sujeto y dialéctica de su deseo en el inconsciente freudiano”. En Escritos 2. México: Siglo XXI, 2001.

Lacan, Jacques. "La angustia en la red de los significantes". En El Seminario. Libro 10. La angustia. Los Seminarios de Jacques Lacan. Buenos Aires: Paidós, 2004.

Lacan, Jacques. "Del cosmos al Unheimlichkeit". En El Seminario. Libro 10. La angustia. Los Seminarios de Jacques Lacan. Buenos Aires: Paidós, 2004.

Lacan, Jacques. "De los Nombres del Padre". En El Seminario. Libro 10. La angustia. Los Seminarios de Jacques Lacan. Buenos Aires: Paidós, 2004.

Lacan, Jacques. "Del uso lógico del sinthome o Freud con Joyce”. En Seminario 23. El sinthome. Los seminarios de Jacques Lacan. Buenos Aires: Paidós, 2005.

Lacan, Jacques. "De lo que agujera lo real". En Seminario 23. El sinthome. Los seminarios de Jacques Lacan. Buenos Aires: Paidós, 2005.

Lacan, Jacques. “¿Qué es un cuadro?”. En Seminario 11. Los cuatro conceptos fundamentales del psicoanálisis. Los seminarios de Jacques Lacan. Buenos Aires: Paidós, 2009.

McGennis, Aidan. (2014) “Louis Wain. His Life, his Art and his Mental Illness". Irish Journal of Psychological Medicine 16, núm. 1 (2014). https://doi.org/10.1017/S0790966700005000.

Motta, Carlos. "Psicoanálisis y arte: respuesta al vacío". Virtualia, Revista Psicoanalítica de la EOL IX, núm. $20 \quad$ (2010): 2-6. http://www.revistavirtualia.com/articulos/381/arte-de-psicoanalistas/psicoanalisis-yarte-respuesta-al-vacio. 


\section{enn-claves}

Palencia Galán, Leandro. "Las estructuras formales del arte y del psicoanálisis ¿se puede tumbar el arte al diván?”. Aletheia, núm 28 (2008): 21-31. http://pepsic.bvsalud.org/pdf/aletheia/n28/n28a03.pdf.

Soler, Colette. "El trabajo de la psicosis". En Estudios sobre psicosis. Buenos Aires: Manantial, 1991.

Soler, Colette. "El cuerpo en la enseñanza de Jacques Lacan”. Agape Psicoanalítico (2013): 1-7. https://agapepsicoanalitico.files.wordpress.com/2013/07/colettesolerelcuerpoenlaensenanzadejacqueslacan.pdf.

Yiannaka, María. La expresión plástica como alternativa de comunicación en pacientes esquizofrénicos: arteterapia y esquizofrenia [Tesis] División Bellas Artes, Universidad Complutense de Madrid, España, 2001. http://eprints.ucm.es/4856/1/T25317.pdf. 